\title{
The effect of time and site on incidence and spread of pruning-related decay in plantation- grown Eucalyptus nitens
}

\author{
Karen M. Barry, Malcolm F. Hall, and Caroline L. Mohammed
}

\begin{abstract}
Quantitative information on stem decay in eucalypt plantations grown for solid wood products, with consideration of the effect of site, pruning, and spread of decay with time, is required for the prediction of harvest yield and quality. A trial at three Eucalyptus nitens (Dean \& Maiden) Maiden plantations in Tasmania revealed that the effect of time on the number and size of decay columns was substantially greater than the effect of site or of whether trees were pruned or not. Length of decay columns was 3.4-fold greater on average for the trees assessed 5.5 years after pruning than at 1 year. All decay columns in pruned trees were restricted to the knotty core, and the amount of decay-free clearwood increased over time. A controlled wounding trial showed that decay in sapwood was not significantly different in length with site but was mainly determined by the fungal species used. Ongoing research to monitor the spread of decay in pruned plantation-grown E. nitens will be important to enable prediction of the future impact of decay on harvest yields of solid wood products.

Résumé : Il est nécessaire d'avoir des données quantitatives sur la carie de tronc dans les plantations d'eucalyptus destinées à la production de bois d'œuvre pour prédire le rendement et la qualité lors de la récolte en tenant compte de l'effet de la station, de l'élagage et de la progression de la carie dans le temps. Une étude réalisée dans trois plantations d'Eucalyptus nitens (Dean \& Maiden) Maiden, en Tasmanie, a révélé que l'effet du temps sur le nombre de colonnes de carie et sur leur dimension est substantiellement plus important que celui de la station ou du fait que les arbres aient été élagués ou non. Les colonnes de carie étaient en moyenne 3,4 fois plus longues chez les arbres examinés 5,5 ans plutôt qu'un an après avoir été élagués. Toutes les colonnes de carie dans les arbres élagués étaient limitées au nœud lui-même et la quantité de bois clair, exempt de carie, augmentait avec le temps. Un test avec des blessures standardisées a démontré que la longueur de la carie dans le bois d'aubier n'était pas significativement différente selon la station mais qu'elle était principalement déterminée par l'espèce de champignon utilisée. Les travaux de recherche en cours pour suivre le développement de la carie dans les plantations de E. nitens seront importants pour être en mesure de prédire l'impact futur de la carie sur les rendements en produits de bois massif au moment de la récolte.
\end{abstract}

[Traduit par la Rédaction]

\section{Introduction}

Stem decay in trees can have a considerable impact on harvest yield and on the quality of solid wood products in an industrial context (Wardlaw and Neilsen 1999). Information on stem decay in native Australian eucalypt forests has been gathered for many years (e.g., Rudman 1965; Wilkes 1982, 1985; White and Kile 1993, 1994; Wardlaw 1996), but quantitative studies of stem decay in eucalypt plantations are few (e.g., Yang and Waugh 1996; Wardlaw and Neilsen 1999; Mohammed et al. 2000).

Some plantation eucalypts, such as Eucalyptus nitens (Dean \& Maiden) Maiden retain dead branches, and these require pruning to produce knot-free timber (clearwood), a practice that creates infection courts for decay fungi. To investigate decay incidence and factors influencing the initial infection of pruning wounds, a study of E. nitens was established in Tasmania in 1996 (Mohammed et al. 2000). The trial showed that after 1 year pruned branches were associated with decay columns to a much greater extent than unpruned branches and that pruning technique (e.g., use of "standard practice" pruning shears; damage to the branch collar with a saw) had a significant effect on decay. The trial demonstrated that probability of decay was related to branch size, angle, and status (e.g., alive, dead, senescent), which varied with site. The current study is based on assessments after 5.5 years of the standard practice pruning treatments of this trial.

Received 11 May 2004. Accepted 29 October 2004. Published on the NRC Research Press Web site at http://cjfr.nrc.ca on 16 March 2005.

K.M. Barry. ${ }^{1}$ School of Agricultural Science, University of Tasmania, Private Bag 54, Hobart 7001, Tasmania, Australia; and Cooperative Research Centre for Sustainable Production Forestry, Private Bag 12, Hobart 7001, Tasmania, Australia.

M.F. Hall. CSIRO Forestry and Forest Products, Private Bag 12, Hobart 7001, Tasmania, Australia.

C.L. Mohammed. School of Agricultural Science, University of Tasmania, Private Bag 54, Hobart 7001, Tasmania, Australia; Cooperative Research Centre for Sustainable Production Forestry, Private Bag 12, Hobart 7001, Tasmania, Australia; and CSIRO Forestry and Forest Products, Private Bag 12, Hobart 7001, Tasmania, Australia.

${ }^{1}$ Corresponding author (e-mail: Karen.Barry@ffp.csiro.au). 
Table 1. Details of the three sites used for the current study.

\begin{tabular}{|c|c|c|c|}
\hline & Evercreech 108A & Flowerdale 37D & Hastings 28B \\
\hline Latitude and longitude & $41^{\circ} 20^{\prime} \mathrm{S}, 147^{\circ} 55^{\prime} \mathrm{E}$ & $41^{\circ} 04^{\prime} \mathrm{S}, 145^{\circ} 29^{\prime} \mathrm{E}$ & $43^{\circ} 24^{\prime} \mathrm{S}, 146^{\circ} 53^{\prime} \mathrm{E}$ \\
\hline Approximate location & $\begin{array}{l}\text { Dilgers Road, } 25 \mathrm{~km} \\
\mathrm{~N} \text { of Fingal }\end{array}$ & $\begin{array}{l}\text { Meunna Road, } 3 \mathrm{~km} \mathrm{~N} \text { of Meunna, } \\
20 \mathrm{~km} \mathrm{~S} \text { of Sisters Creek }\end{array}$ & $\begin{array}{l}\text { Creekton Road - Tughanah Road, } \\
30 \mathrm{~km} \mathrm{~S} \text { of Geeveston }\end{array}$ \\
\hline Parent material & Devonian granite & Tertiary basalt & Triassic sediments and dolerite talus \\
\hline Fertility & High & High & Medium \\
\hline Altitude ( $\mathrm{m}$ above sea level) & 635 & 260 & 140 \\
\hline Average height $( \pm \mathrm{SE})(\mathrm{m})^{*}$ & $20.62(0.36)$ & $17.18(0.35)$ & $20.94(0.75)$ \\
\hline $\begin{array}{l}\text { Average diameter at breast } \\
\text { height }( \pm \mathrm{SE})(\mathrm{cm})^{*}\end{array}$ & $19.78(0.77)$ & $20.12(0.79)$ & $18.39(1.21)$ \\
\hline
\end{tabular}

*Data from trees harvested in 2002 for the pruning studies only.

Although a few decay studies have been completed in pruned plantation eucalypts (Gadgil and Bawden 1981; Wardlaw and Nielsen 1999; Mohammed et al. 2000) questions remain about how far decay will spread over time and whether the factors explored above will remain significant over the longer term. In well-described tree-pathogen systems where one fungal species causing decay is apparent (identified by the presence of a fruitbody), inferences can be made about the likelihood of decay spreading through barriers such as reaction zones (Schwarze et al. 2000). This information has been developed for some European urban tree-pathogen systems, where tree hazard and amenity value are important, but indications of decay spreading rates rely on expensive, noninvasive tomographic methods. This system is currently not feasible for industrial plantation trees where fruitbodies are not produced and the large-scale use of noninvasive technologies is too costly.

The most effective way, therefore, to predict the spread of decay is to destructively assess a sample of trees at various periods after pruning. Informative measurements include the number of individual decay columns, the length and width of columns, and position in cross section. A number of destructive studies of regrowth eucalypts have identified changes in amount of decay with increasing age (Wardlaw 1996; Wardlaw et al.1997). Although these studies were of much older trees, and the growth conditions differ between regrowth forests and plantations, it is of interest that the increase in decay was mostly attributable to a greater number of decay columns over time. In Eucalyptus regnans F. Muell and Eucalyptus delegatensis R.T. Baker, Wardlaw (1996) found agerelated increases in the incidence of decay, but not in column size. Similarly, across 20 coupes of final-crop regrowth eucalypts, Wardlaw et al. (1997) found that tree age was positively and significantly correlated with the number of decay columns. In wounding studies of 20-year-old regrowth E. regnans, White and Kile (1993) found significant differences in the extent of decay above wounds 6-12 months later, but not after 24 months.

In pruned trees, increases in the number of decay columns and their length are not necessarily important if the decay remains within the knotty core. Spread of decay into clearwood (depending on the extent and intensity) will likely result in a downgrade of sawlogs to pulpwood. For regrowth eucalypts, this will amount to a $7 \%$ loss in revenue from stumpages, according to current specifications, and greater losses if speci- fications are tightened (Wardlaw 2003). In two studies of plantation eucalypts (pruned E. regnans and E. nitens) there is little evidence of decay spreading into clearwood (Somerville and Davies-Colley 1998; Wardlaw and Neilsen 1999, respectively). The length of the decay columns is likely to be important if more than one pruning lift is completed. That is, large decay columns from the second lift could spread far enough to penetrate the clearwood of the first lift log (approx. $2.5 \mathrm{~m}$ ) (T. Wardlaw, personal communication, 2003). Similarly, decay establishing in dead branches above the pruned log section could spread downwards into clearwood.

Because of these issues, it is important to establish not just whether total decay volume increases over time but where that increase occurs. The main pruning study presented here aimed to quantitatively assess the amount of decay in pruned and unpruned plantation-grown E. nitens at three sites in Tasmania. The trees were assessed 5.5 years after pruning, and results were compared with those from a previous study at the same sites, where assessments were made 1 year after pruning. The wounding trial, a controlled study to compare decay spread between the sites, removed the factor of branch size and sought to control the taxon of decay fungi.

\section{Materials and methods}

\section{Pruning trial}

A pruning trial of E. nitens was established in 1996 at five different plantation sites in Tasmania, and trees were harvested 1 year after pruning (Mohammed et al. 2000). The current study used three of the best growing sites (which might realistically be expected to produce sawlogs) to assess the spread of decay 5.5 years after pruning and compare it with the data collected 1 year after pruning.

\section{Sites}

The five original trial sites covered a range of geology, altitude, and rainfall categories. Trees at all experimental sites were planted in 1992, and the first pruning lift was done in 1996. The three plantations reassessed for the present study were within performance guidelines for veneer and sawlog production (Table 1).

\section{Design and pruning treatments}

The area of each trial site was approximately 1 ha. Ten replicates of each treatment were laid out in completely ran- 
Fig. 1. Measurements recorded when decay was present. Data were used in the following way: the length of decay is $u+d$; the width of decay is the greater of $b_{3}-b_{1}$ and $a_{3}-a_{1}$; and the distance from cambium to decay is the smallest of $b_{3}$ and $a_{3}$.

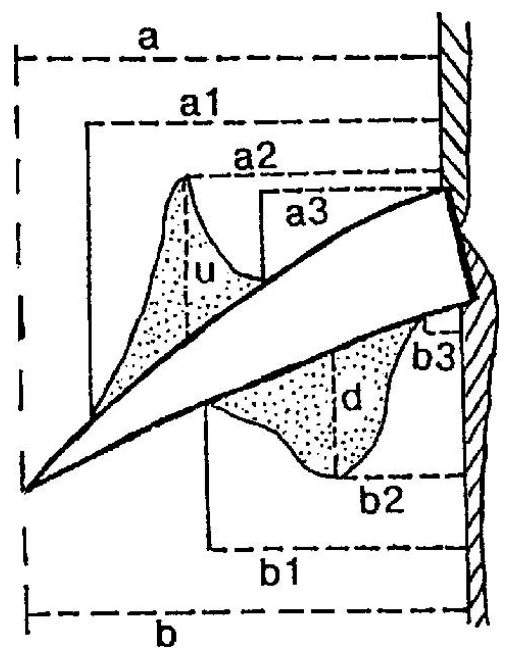

domized blocks of 36 trees each $(6 \times 6$ block $)$ such that a two-tree buffer existed between any two blocks. Within each block, 16 trees of commercially prunable quality were selected. These 16 trees were randomly allotted one of 16 treatments, which included standard pruning (with shears) and unpruned treatments, both at four different times of year (January, April, July, October). Four alternative pruning treatments (painting the pruning wound with a sealant or with a sealant with fungicide; damaging the branch collar; leaving a branch stub after pruning) were done in only two seasons. Bacseal $^{\mathrm{TM}}$ pruning paint (Bayer, Sydney) was used as a sealant that included two fungicides, biteranol (10g/L) and 8hydroxyquinoline sulphate $(10 \mathrm{~g} / \mathrm{L})$, or it was specially formulated without the fungicides. The 16 tree treatments in each block $(=800$ trees, or 16 trees per block $\times 10$ blocks $\times$ 5 sites) were completed by January 1997. One year after treatments were applied, approximately 500 trees of the trial were harvested and analysed for decay (Mohammed et al. 2000).

\section{Harvest in 2002}

Of the 16 treatments, those harvested in 2002 included a number of replicates remaining from the standard prune and unpruned July and January treatments. One tree of each treatment from five blocks was harvested at each of three sites. Trees pruned in July were harvested and assessed in January 2002, and trees pruned in January were harvested and assessed in July 2002; therefore, in both cases the assessment occurred 5.5 years after pruning. A total of 60 trees were harvested and assessed.

\section{Assessment of decay}

The height and diameter at breast height (DBH) of each tree were measured before treatment (1996-1997), and the north-facing side was marked on the stem with paint. The status of each branch (live, dead, senescent) was marked on a grid plotting the cardinal points against height above ground. Branches were mapped up to pruning height $(2.5 \mathrm{~m})$.
Upon harvesting, the height and $\mathrm{DBH}$ of the trees were remeasured. Logs from the first $2.8 \mathrm{~m}$ were transported to the laboratory. Each branch was allocated a number, the status at pruning was determined from earlier data, and the degree of branch occlusion was recorded. The logs were cross-cut with a chainsaw, and then each branch was dissected with a bandsaw to allow internal inspection. For each branch, the branch diameter (millimetres) was measured under bark at the junction with the stem, and the branch angle from vertical was recorded. Branches that were self-pruned were recorded. Where decay was observed spreading from a branch, the length and width of the decay column, as well as its distance from cambium, was measured (millimetres) above and below the stub (Fig. 1). All procedures were identical to those used when data were collected 1 year after pruning.

\section{Data analysis and statistics}

Branches that were self-pruned were included in all analyses, as they constituted a large proportion of the branches of some unpruned trees after 5.5 years. These branches had been excluded from original data collected 1 year after pruning, so self-pruned branches were factored back into the data set for completeness.

A number of strategies were used to analyse the data statistically, including comparisons of results from the current study with those obtained 1 year after pruning. As pruning at different times of year did not exert a significant influence on the level of decay, according to results after 1 year (Mohammed et al. 2000), and any seasonal effect tends to decrease with time (White and Kile 1993), the July and January prune treatments have been pooled.

Three-way analysis of variance (ANOVA) was conducted with SAS for Windows, version 8 (SAS 1999), using fixed factors of site, time since pruning, and treatment (pruned or control). To improve homoscedasticity and account for zeros when assessing the number of decay columns, we used the log of raw data plus one. When length of decay columns was assessed, data for each tree were expressed as an average of the data for all the decay columns in that tree. Trees with no recorded decay columns were entered as missing data (rather than zero), and logged data were used. A Ryan-Einot-GabrielWelsch multiple range test (REGWQ test) was conducted with SAS for Windows, version 8 (SAS 1999), to determine the within-experiment statistical differences $(P<0.05)$ where there was no significant interaction between factors detected from the ANOVA.

\section{Wounding trial}

\section{Sites and design}

The same three sites described above were used. Four unpruned trees per site were selected, and care was taken care to avoid those with large branches or obvious stem wounds.

\section{Preparation of fungal inocula}

Two fungi were chosen for inoculation: Phellinus gilvus (Schwein.:Fr.) Pat. (CSIRO Clayton fungal collection, isolate No. 2374) and an unknown isolate obtained from previous decay studies of plantation trees at Flowerdale, Tasmania (isolate F13a). This isolate was identical to isolate D (or E99/1) used by Barry et al. (2002) and this was confirmed 
Fig. 2. Wounding pattern, where aspect was either north (a), southwest (b), or southeast (c). Fungal treatments were control (1), Phellinus gilvus (2), and F13a (3).

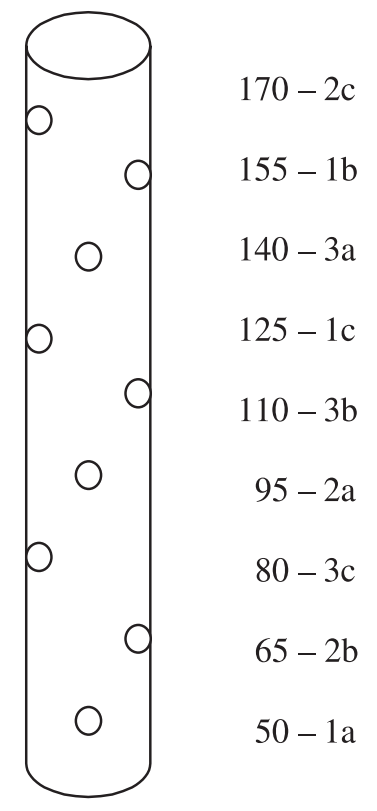

by restriction fragment-length polymorphism molecular studies (Harrison 2000). The isolate causes a white rot, has a radial growth rate of $30-37 \mathrm{~mm}$ (after 7 days at $20{ }^{\circ} \mathrm{C}$ on $2 \%$ maltextract agar (MA)), clamps at all septa in marginal and aerial hyphae, and produces laccase and peroxidase. Identification with the use of Nobles (1948), Stalpers (1978), or Nakasone (1990) keys has not been successful. Analysis of ribosomal DNA sequences (the 370-bp small subunit, the 600-bp large subunit, the entire ITS I and ITS II regions, and the 5.8S subunit) places this isolate in either Lentinaceae or Polyporaceae of the Aphyllophorales (M. Glen and S. Abou Arra, unpublished data). Phellinus gilvus had a radial growth rate of 20-25 mm (after 7 days at $20{ }^{\circ} \mathrm{C}$ on $2 \%$ MA). Phellinus gilvus causes a white-pocket rot in Eucalyptus crebra F. Muell and Eucalyptus diversicolor F. Muell and butt rot associated with wounding in Eucalyptus grandis W. Hill ex Maiden and Eucalyptus saligna Smith (Kile and Johnson 2000). This fungus was chosen for use as it is slower growing than isolate F13a. Cultures were grown on $2 \%$ MA at $20{ }^{\circ} \mathrm{C}$ in the dark.

Wood chips of fresh E. nitens stems were prepared with a chainsaw and sterilized in an autoclave. Wood chips were added to the top of agar cultures for inoculation and were incubated at $20{ }^{\circ} \mathrm{C}$ in the dark for at least 6 weeks.

\section{Wounding and inoculation procedure}

Trees were wounded and inoculated during the summer (January and February) of 2002 at each site. Nine holes per tree were created, starting at a northern aspect at $50 \mathrm{~cm}$ above ground level. There was $15 \mathrm{~cm}$ between each wound, and the wounds were offset by $120^{\circ}$ (Fig. 2). Wounds were inoculated with either a control or one of the fungal treatments.

Drill holes were made at the positions described with an engine drill (Tanaka) with a $16 \mathrm{~mm}$ diameter auger bit. Drill holes were approximately $8 \mathrm{~cm}$ deep and made at a slight upwards angle. Sterile implements were used to immediately fill the holes with the wood chip inoculum, and the holes were sealed immediately with Vaseline ${ }^{\mathrm{TM}}$.

\section{Assessment}

After approximately 4 months, wounded trees were harvested, and the first $2.5-\mathrm{m} \log$ was brought back to the laboratory. Total tree height and $\mathrm{DBH}$ were recorded when trees were felled. Logs were cut into short billets with a chainsaw, and then a bandsaw was used to slice through the middle of wounds for assessment of decay spread. Decay and (or) discolouration were measured in both the sapwood and heartwood; these measurements included maximum length and width and the distance from the cambium to the point of maximum length. Although sapwood infection was quite distinct, heartwood was usually infected (discoloured) to a greater extent in width and length. As wounds were reasonably close together (although offset in orientation), it was commonly found that heartwood discolouration from one wound merged with that from another wound. Therefore, measurement of the spread of discolouration in the heartwood was not always possible.

\section{Reisolation of fungi}

For each wound, four or five wood chips from each of the infected sapwood (above or below) and heartwood (above or below) were sampled aseptically and placed onto $2 \% \mathrm{MA}$ and $1 \%$ malt extract selective for basidiomycetes (Barry et al. 2002). Plates were incubated at $20{ }^{\circ} \mathrm{C}$ in the dark for approximately 3 weeks. Resulting fungal growth was recorded, and the morphology of decay-like fungi (i.e., nonascomycete, nonyeast) was detailed. These fungi were subcultured for future reference and compared with the initial species inoculated.

\section{Data analysis}

The wounding trial was analysed as a nested design: tree (four per site) was the true replicate, and wound (nine per tree of three different treatments) was the nested factor. A two-way ANOVA was conducted with SAS for Windows, version 8 (SAS 1999), using the fixed factors site and inoculum, with the response variable being length of sapwood decay.

\section{Results}

\section{Pruning trial}

\section{Number of decay columns}

Three-factor ANOVA for the number of decay columns revealed an overall statistical significance $(P<0.0001)$. Time after pruning was the most significant factor $(P<0.0001)$, followed by a site $\times$ time interaction $(P<0.0022)$ and treatment $(P<0.0076)$. Higher order interactions were not significant. The number of decay columns present ranged from as low as 0.2 on average per tree (i.e., two columns detected in 10 trees) for the unpruned control trees at Hastings after 1 year to 4.6 on average per tree for the pruned trees at Flowerdale after 5.5 years (Table 2).

Except for the pruned trees at Hastings, for all treatments at all sites more decay columns were detected after 5.5 years than after 1 year after pruning. For example, there was a 3fold greater number of decay columns in the pruned trees at Evercreech and a 5.4-fold greater number of decay columns for the unpruned control Flowerdale trees over time (Ta- 
Table 2. Average number of decay columns per tree $( \pm \mathrm{SE})$ in Eucalyptus nitens 1 and 5.5 years after pruning at three sites.

\begin{tabular}{|c|c|c|c|c|c|c|}
\hline \multirow[b]{2}{*}{$\begin{array}{l}\text { Time since } \\
\text { pruning (years) }\end{array}$} & \multicolumn{2}{|l|}{ Flowerdale } & \multicolumn{2}{|l|}{ Evercreech } & \multicolumn{2}{|l|}{ Hastings } \\
\hline & Pruned & Control & Pruned & Control & Pruned & Control \\
\hline 1 & $2.3( \pm 0.6)$ & $0.8( \pm 0.3)$ & $1.1( \pm 0.7)$ & $0.6( \pm 0.3)$ & $1.7( \pm 0.6)$ & $0.2( \pm 0.1)$ \\
\hline 5.5 & $4.6( \pm 0.9)$ & $4.1( \pm 0.8)$ & $3.4( \pm 0.9)$ & $1.4( \pm 0.5)$ & $0.8( \pm 0.6)$ & $0.6( \pm 0.3)$ \\
\hline
\end{tabular}

Fig. 3. Averages for decay column measures from each site 1 and 5.5 years after pruning, assessed as severity of decay due to incidence. (A) Length of decay columns (combined above and below branch). (B) Width of decay columns (maximum). (C) Distance from cambium to decay column (minimum). White bar, pruned 1 year ago; white bar with stipple, pruned 5.5 years ago; grey bar, control after 1 year; grey bar with stipple, control after 5.5 years.

\section{(A) Average decay length $(\mathrm{mm})$}

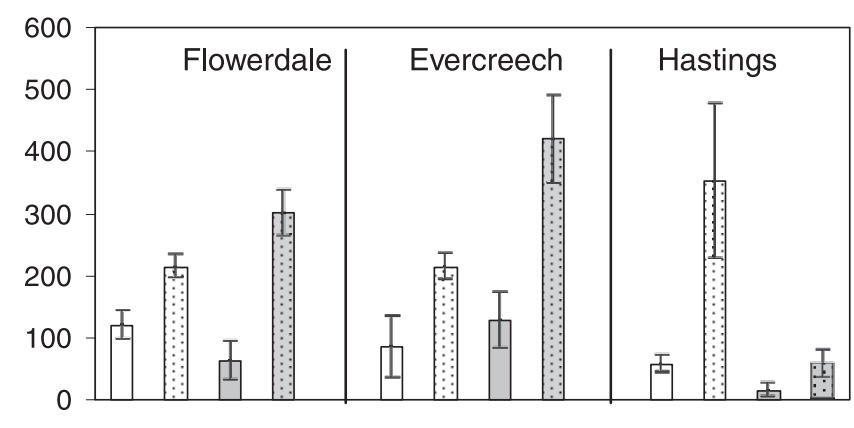

\section{(B) Average decay width $(\mathrm{mm})$}

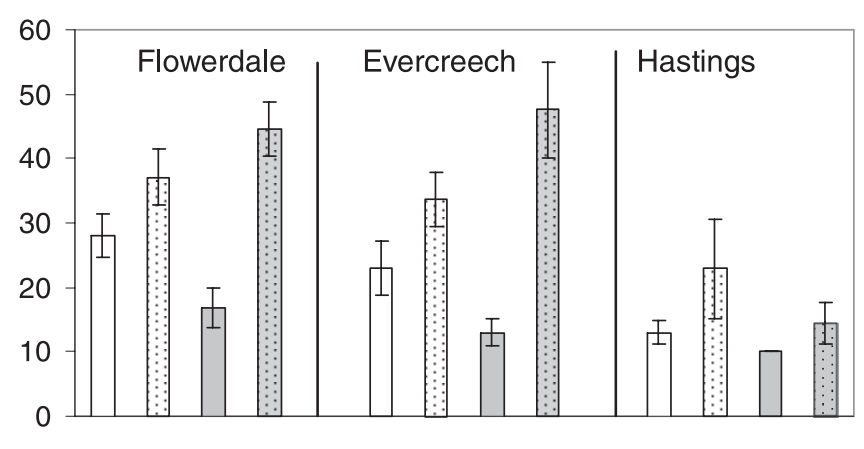

(C) Distance from cambium to decay $(\mathrm{mm})$

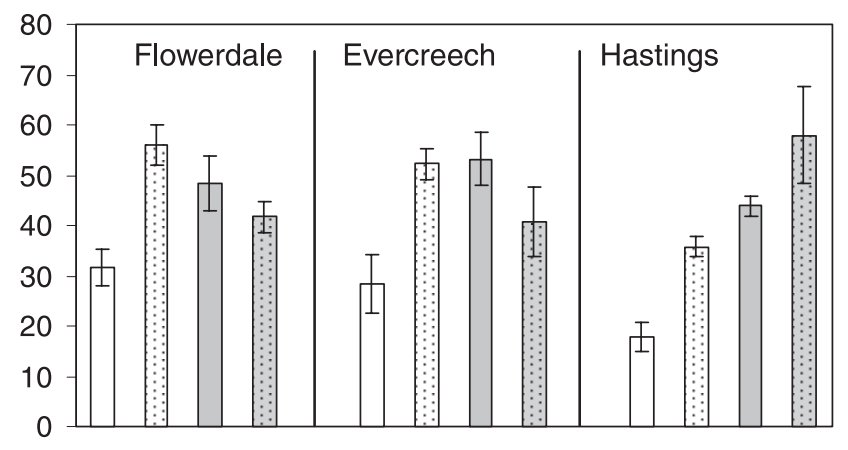

ble 2). Comparing sites, we note that Flowerdale remained the most decay prone after 5.5 years. The differences between pruned and unpruned trees detectable at 1 year after pruning disappeared at Flowerdale and Hastings after 5 years (Table 2).

\section{Decay column length and width}

The data were first prepared by averaging the length of all decay columns present per treatment, time, and site (Fig. 3); zero scores were used for trees with no decay columns. Therefore, these data are an expression of severity of decay due to incidence. The length of the decay columns was always greater in the trees assessed after 5.5 years than in those assessed 1 year after pruning, regardless of site or treatment (Fig. 3A). Overall, decay columns measured 5.5 years after pruning were 3.4 times as long $(260 \mathrm{~mm})$ as those measured 1 year after pruning $(77 \mathrm{~mm})$. For example, the three longest individual decay columns (arising from a single branch) found 1 year after pruning were 580, 242, and $184 \mathrm{~mm}$, but after 5.5 years the longest were 1910, 1088, and $860 \mathrm{~mm}$. At Flowerdale and Evercreech the control (unpruned) trees had longer decay columns than the pruned trees by 5.5 years after pruning, but this was not consistent for Hastings (Fig. 3A). Overall, the length of decay columns across the sites was similar for the columns arising from pruned trees $(173 \mathrm{~mm})$ and control trees $(164 \mathrm{~mm})$.

As differences in the length of decay columns between treatments and sites appeared to be significant (Fig. 3A), ANOVA was conducted on the length data. For this ANOVA, average lengths for the decay columns within each tree were created, and where individual trees had no decay columns present, a missing value was used (there were 50 missing values from the 120 trees). Therefore, the results express severity of decay according to extent and do not incorporate incidence. This produced slightly different means than in Fig. 3A, but trends were generally the same. Where many long decay columns were recorded (that is, 5.5-year Evercreech controls and 5.5-year Hastings pruned trees), the averages were accentuated when results were averaged on a tree by tree basis.

The ANOVA revealed overall significance $(P<0.0001)$ for length of decay columns. Time explained most of this significance $(P<0.0001)$, followed by site $(P<0.0232)$. The second-order interactions were not significant, although the highest order ( site $\times$ time $\times$ treatment) was marginally significant $(P=0.0375)$.

The average width of decay columns revealed trends (Fig. 3B) similar to those of the length measurements. Averages of the distances of decay column edges to the cambium (Fig. 3C) were reduced over time in the unpruned trees (except for Hastings) but increased in the pruned trees (all three sites). 
Table 3. Number of subcultured potential decay-causing isolates grouped into morphological types by site.

\begin{tabular}{llllll}
\hline Site & Type A & Type B & Type C & Other & Total \\
\hline Flowerdale & 13 & 16 & 10 & 17 & $56(48 \%)$ \\
Evercreech & 3 & 11 & 9 & 9 & $32(27 \%)$ \\
Hastings & 2 & 6 & 8 & 12 & $28(25 \%)$ \\
Total & $18(16 \%)$ & $33(28 \%)$ & $27(23 \%)$ & $38(33 \%)$ & 116 \\
\hline
\end{tabular}

Fig. 4. Average decay column length of wounded and inoculated Eucalyptus nitens at three sites in Tasmania (four trees per site; nine wounds per tree). White bar, control; light grey bar, Phellinus gilvus; dark grey bar, F13a.

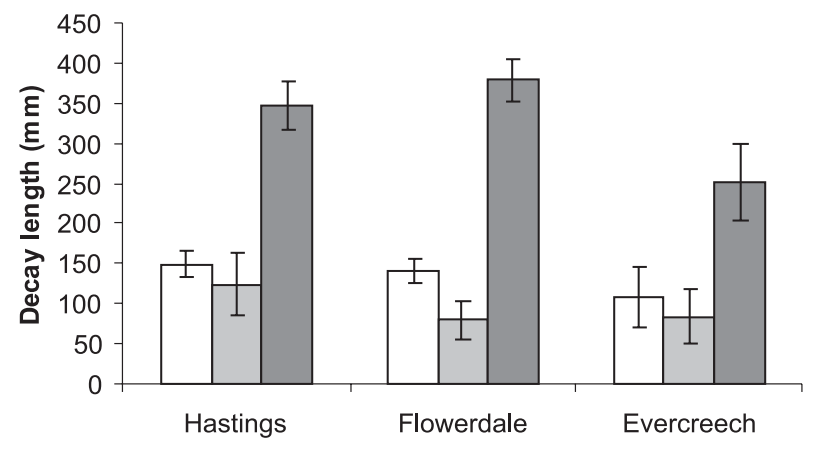

\section{Wounding trial}

\section{Reisolation of inoculated fungi}

Isolate F13a was successfully reisolated from decay columns of all 36 wounds that had been inoculated with it. It was consistently reisolated from the decayed sapwood and discoloured heartwood. Control wounds were often infected and associated with some decay or discolouration. Wounds inoculated with $P$. gilvus were always colonized by a different fungus, and $P$. gilvus was never reisolated. Of the unidentified fungi there were 116 subcultured potential decay-causing isolates (basidiomycetes and xylariaceae), and representative nondecay fungi were subcultured in addition (e.g., Trichoderma spp., Penicillium spp.).

Decay-causing isolates were grouped according to morphological appearance, and although there was a great diversity in the isolates obtained, three main types accounted for $66 \%$ of the isolates (Table 3). These included type A (light transparent mycelium), type B (thick white mycelium, sometimes growing in clumps), and type $\mathrm{C}$ (xylariaceae-like, radial tufts, with black colour starting in the middle). The type B fungi were similar to isolate F13a (isolate D, Barry et al. 2002), and the type A were similar to isolate R (Barry et al. 2002). The three main types of isolate were found at each of the sites, although in different proportions (Table 3).

\section{Decay spread}

Of the three fungal treatments, isolate F13a was associated with the longest decay columns in the sapwood (Fig. 4). This isolate grew well in the woodchip inoculum (offering a greater inoculum potential) and had a faster growth rate in culture than $P$. gilvus did. The ANOVA conducted on decay length results confirmed that the effect of different fungi was the most significant factor $(P<0.0001)$, whereas site was not significant. There were no significant interactions. The
REGWQ test showed that the isolate F13a treatments were distinct from the other treatments. Therefore, this study has revealed that when wound size and fungal inoculum are controlled (although only in the F13a treatment), there is no apparent effect of site.

Although it was difficult to determine actual sizes of discolouration occurring in the heartwood, the discolouration was usually greater in length than the sapwood decay. Decay was occasionally recorded as present in the heartwood, and it was often found as flecks rather than distinct columns. The sapwood decay was almost always as wide as the sapwood present at the time of wounding (at the point of the wound, then narrowing toward the end of the column), and the heartwood discolouration was usually as wide as or wider than the width of the heartwood that was penetrated with the drill wound. It was not possible to determine whether a quantitative relationship existed between the amount of sapwood decay and the amount of heartwood discolouration for a given wound or tree.

\section{Discussion}

The significantly greater number of decay columns found over time in plantation E. nitens follows the same trend as in regrowth eucalypts. For example, in two regrowth plots of E. regnans and E. delegatensis, the older trees had significantly more decay columns (Wardlaw 1996). However, for the size of decay columns, we found significant increases over a relatively short time in plantation E. nitens, but this has generally not been the case for regrowth eucalypts aged up to 20-30 years (e.g., Wardlaw 1996; Wardlaw et al. 1997).

Understanding the direction of decay spread is an important way of determining the final effect on wood products. Patterns of decay observed in the E. nitens sapwood are explained by processes of compartmentalization, as previously discussed (Barry 2001; Barry et al. 2000, 2001, 2002). In the wounded trees, decay was restricted in the extant sapwood by a barrier zone; beyond the wound, reaction zones restricted tangential and radial spread. Decay columns are likely to continue spreading over time mostly in the axial direction, as reaction zones are less effective in this direction (Barry et al. 2000, 2001, 2002). Heartwood was discoloured but not extensively decayed, which is explained by the infiltration of polyphenols as heartwood forms (Barry 2001).

Key results of the pruning study were that all decay columns in pruned trees were restricted to the knotty core and that the amount of decay-free clearwood increased over time. The unpruned trees generally had smaller measures of decayfree clearwood (i.e., the distance from the cambium to the decay), which implies that these decay columns became established later than those in pruned branches. This is understandable on the basis that pruned branches are likely to 
become infected at the time of pruning, whereas unpruned branches may become foci for decay at a range of times, depending on when the branch senesces or if it becomes damaged.

The main outcome of the wounding trial was that the decay in sapwood was not significantly different in length with site but was mainly determined by the fungal species used. This was accounted for by the rapid infection by isolate F13a, which resulted in significantly greater decay columns than the other two treatments. Although trees in these two treatments became infected with a range of fungi, the decay associated with $P$. gilvus inoculation was significantly less than the decay associated with the control at one site (Evercreech); therefore, the treatments warrant separate assessment. Reisolations revealed the large diversity of fungal species capable of invading stem wounds in E. nitens plantations in Tasmania, which supports the findings of previous studies (Harrison 2000). We found that three main groups (although only determined by cultural morphology) accounted for about $50 \%$ of isolations, and this is comparable to the findings with E. delegatensis in New Zealand, where one fungus accounted for $12.4 \%$ of all isolates (Gadgil and Bawden 1981).

The wounding trial confirmed that when branch factors were removed, wound size was constant, and fungal species were "controlled" (at least for the F13a treatment), the site effect was not significant. Therefore a combination of branch factors and fungal biodiversity is probably responsible for the significance of the site factor (interacting with time) detectable in the pruning trial. Although the site factor was significant, it was secondary to time for both number and size of decay columns; therefore, predictions of decay spread among sites of similar environment may be generalizable, especially in the longer term.

The assessment of decay 1 year after pruning at five Tasmanian sites found larger differences in the incidence and extent of decay with site, as the assessment included three productive and two less productive sites (Mohammed et al. 2000), whereas the present study has assessed the three most productive sites only. The differing result is probably mostly related to branch size and status (e.g., proportion of dead branches), because the drier and less productive sites had a higher proportion of dead branches and therefore less decay (Mohammed et al. 2000). Trees at sites of similar productivity would be expected to have a more similar complement of branch status. Additional studies in Tasmania have shown that the effect of fertilization on growth (especially branch size) had a major effect on the incidence of decay in E. nitens (Wiseman et al. 2003). Branch characteristics such as size and death are linked to site factors in other plantation trees, such as Scots pine (Mäkinen 1999), and this can sometimes be linked to decay risk in other cases, for example, in tropical Acacia mangium Willd. (Lee and Arentz 1997).

The pruning trial also revealed that the effect of time was greater on the number of decay columns and their size than whether trees were pruned or not (i.e., treatment). While treatment was significantly contributing to the number of decay columns, it was not a significant determinant of column size. Therefore, as time progresses the effects of pruning treatment on the total decay volume may diminish in comparison to unpruned trees. This gives support to the current practice of pruning branches to increase clearwood produc- tion in E. nitens (and E. globulus), as it may have no added detrimental affects on decay incidence in the longer term, compared with leaving the trees unpruned. Further studies on other plantation eucalypt species that support this finding would be extremely valuable, as other species of Eucalyptus are currently being planted in Australia with the expectation of solid wood production (Montagu et al. 2003).

\section{Conclusion}

This study highlights the extent to which decay spreads over time in E. nitens stems grown in Tasmania. Although this study reveals that decay does not enter the clearwood within 5.5 years, and other studies have been done at up to 9 years after pruning (Wardlaw and Neilsen 1999), rotation lengths of 25-30 years may be required to produce sawlogs from these sites. Ongoing research to monitor decay spread in pruned plantation-grown E. nitens will be important to enable prediction of the future impact of decay on the volume of clearwood from pruned stands.

\section{Acknowledgements}

These experiments were completed on Forestry Tasmania plantation sites. Thanks go to Tim Wardlaw for facilitating access to a motorized wheelbarrow to enable logs to be transported at the Hastings site. Ragil Irianto assisted with field work, decay assessment, and the establishment of the wounding trial while visiting from the Ministry of Forestry, Indonesia. Thanks go to Elizabeth Pietryzkowski and Danielle Wiseman for assistance with reisolations. Craig Baillie, Andrew Mitchell, Hilton Redgrove, and Julian Smith assisted with harvests at Hastings. This study was part of the Australianbased component of an Australian Centre for International Agricultural Research (ACIAR) project "Heartrots in Plantation Hardwoods in Indonesia and SE Australia", ACIAR project FST/00/123. Tim Wardlaw and Glen Kile provided valuable comments on an earlier version of this article.

\section{References}

Barry, K.M. 2001. Antimicrobial defence in Eucalyptus nitens sapwood. Ph.D. thesis, University of Tasmania, Hobart.

Barry, K.M., Pearce, R.B., and Mohammed, C.L. 2000. Properties of reaction zones associated with decay from pruning wounds in plantation-grown Eucalyptus nitens. For. Pathol. 30: 233-245.

Barry, K.M., Pearce, R.B., Evans, S.D., Hall, L.D., and Mohammed, C.L. 2001. Initial defence responses in sapwood of Eucalyptus nitens (Maiden) following wounding and inoculation. Physiol. Mol. Plant Pathol. 58: 63-72.

Barry, K.M., Davies, N.W., and Mohammed, C.L. 2002. Effect of season and different fungi on phenolics in response to xylem wounding and inoculation in Eucalyptus nitens. For. Pathol. 32: $163-178$.

Gadgil, P.D., and Bawden, A.D. 1981. Infection of wounds in $E u$ calyptus delegatensis. N.Z. J. For. Sci. 11: 262-270.

Gerrand, A.M., Medhurst, J.L., and Neilsen, W.A. 1997. Thinning and pruning eucalypt plantations for sawlog production in Tasmania. Tasforests, 9: 15-34.

Harrison, K. 2000. Stem decay fungi from plantation eucalypts. B.Ag.Sci. thesis, School of Agricultural Science, University of Tasmania, Hobart. 
Kile, G.A., and Johnson, G.C. 2000. Stems and butt rot of eucalypts. In Diseases and pathogens of eucalypts. Edited by P.J. Keane, G.A. Kile, F.D. Podger, and B.N. Brown. CSIRO publishing, Canberra. pp. 307-338.

Lee, S.S., and Arentz, F. 1997. A possible link between rainfall and heartrot incidence in Acacia mangium? J. Trop. For. Sci. 9: 441-448.

Mäkinen, H. 1999. Growth, suppression, death, and self-pruning of branches of Scots pine in southern and central Finland. Can. J. For. Res. 29: 585-594.

Mohammed, C.L., Barry, K., Battaglia, M., Beadle, C., Eyles, A., Mollon, A., and Pinkard, E. 2000. Pruning-associated stem defects in plantation E. nitens and E. globulus grown for sawlog and veneer in Tasmania, Australia. In The Future of Eucalypts for Wood Products: Proceedings of an IUFRO Conference, Launceston, Australia, 19-24 March 2000. International Union of Forestry Research Organizations, Launceston. pp. 357-364.

Montagu, K.D., Kearney, D.E., and Smith, R.G.B. 2003. The biology and silviculture of pruning planted eucalypts for clear wood production — a review. For. Ecol. Manage. 179: 1-13.

Nakasone, K.K. 1990. Cultural studies and identification of woodinhabiting Corticiaceae and selected Hymenomycetes from North America. Mycol. Mem. 15: 1-412.

Nobles, M.K. 1948. Studies in forest pathology. VI. Identification of cultures of wood-rotting fungi. Can. J. Res. Sect. C, 26: 281431.

Rudman, P. 1965. The causes of natural durability in timber. XIX. Ageing of eucalypt heartwoods and its effect on decay resistance. Holzforschung, 19: 190-195.

SAS Institute Inc. 1999. SAS for Windows. Version 8 [computer program]. SAS Institute Inc., Cary, N.C.

Schwarze, F.W.M.R., Engels, J., and Mattheck, C. 2000. Fungal strategies of wood decay in trees. Springer, Berlin.

Somerville, A., and Davies-Colley, D. 1998. Growth and utilisation of 22-year-old managed Eucalyptus regnans. N.Z. Tree Grower, 19: $21-23$.
Stalpers, J.A. 1978. Identification of wood-inhabiting aphyllophorales in pure culture. Stud. Mycol. 16: 1-248.

Wardlaw, T. 1996. The origin and extent of discolouration and decay in stems of young regrowth eucalypts in southern Tasmania. Can. J. For. Res. 26: 1-8.

Wardlaw, T. 2003. Stem decay in young regrowth eucalypts in Tasmania. Ph.D. thesis, University of Tasmania, Hobart.

Wardlaw, T.J., and Neilsen, W.A. 1999. Decay and other defects associated with pruned branches of Eucalyptus nitens. Tasforests, 11: 49-57.

Wardlaw, T.J., Savva, M.H., and Walsh, A.M. 1997. Stem decay in final-crop eucalypts from regrowth forests identified for intensive management. Tasforests, 9: 123-138.

White, D., and Kile, G.A. 1993. Discolouration and decay from artificial wounds in 20-year-old Eucalyptus regnans. Eur. J. For. Pathol. 23: 431-440.

White, D., and Kile, G.A. 1994. Breakdown of barrier zones and prediction of the spread of discolouration and decay resulting from stem wounds in Eucalyptus regnans and E. obliqua. Eur. J. For. Pathol. 24: 71-78.

Wilkes, J. 1982. Pattern and process of heartrot in Eucalyptus microcorys. Aust. For. 45: 51-56.

Wilkes, J. 1985. Host attributes affecting patterns of decay in a regrowth eucalypt forest. I. Patterns of natural decay. Holzforschung, 39: $17-22$.

Wiseman, D., Barry, K.M., Hall, M., and Mohammed, C.L. 2003. Tree nutrition affects on wood decay associated with pruning wounds in plantation grown Eucalyptus nitens. In Proceedings of the 8th International Congress of Plant Pathology, Christchurch, New Zealand, 2-8 February 2003. p. 152.

Yang, J.L., and Waugh, G. 1996. Potential of plantation-grown eucalypts for structural sawn products. II. Eucalyptus nitens (Dean \& Maiden) Maiden and E. regnans F. Muell. Aust. For. 59: 99107. 